\title{
Maladaptive remodeling of pulmonary artery root autografts after Ross procedure: A proteomic study
}

\author{
Anna Chiarini, MS, ${ }^{\mathrm{a}}$ Ilaria Dal Prà, MS, ${ }^{\mathrm{a}}$ Giuseppe Faggian, MD, ${ }^{\mathrm{b}}$ Ubaldo Armato, MD, ${ }^{\mathrm{a}}$ and \\ Giovanni Battista Luciani, MD
}

\section{ABSTRACT}

Objective: Pulmonary autograft root dilatation is the major long-term complication after Ross procedure and the leading cause for reoperation. However, the mechanisms underlying dilatation remain to be elucidated. This study analyzed the proteomic changes seen in the dilated pulmonary autograft compared with normal pulmonary artery and aorta tissues.

Methods: Pulmonary autograft surgical samples were taken from 9 consecutive patients (mean age $37 \pm 14 ; 15-51$ years) with mean diameters of $5.2 \pm 0.5 \mathrm{~cm}$ $(4.6-5.8 \mathrm{~cm})$ reoperated 8 to 16 years after Ross procedure. Control pulmonary artery and aorta samples were from 7 age- and sex-matched cardiac donors. Tunicae mediae from all samples were processed for proteomic analysis via 2-dimensional electrophoresis, matrix-assisted-laser-desorption-ionization-time of flight/mass spectrometry, and bioinformatics. The thus-identified putatively relevant proteins were validated via Western immunoblotting.

Results: Pulmonary autograft proteome features differed markedly from control pulmonary arteries, since proteins related to focal adhesions (eg, paxillin), cytoskeleton (eg, vimentin), and metalloprotease-regulating proteoglycans (eg, testican-2) were significantly up-regulated, whereas significant decreases occurred in microfibril-associated glycoprotein1, which controls elastic fiber buildup. Profound changes also occurred in cell-signaling proteins, ie, increases in soluble Jagged-1 fragment and ectodysplasin-2 receptor, and decreases in Notch-1 intracellular domain fragment. Moreover, pulmonary autograft expression levels of Paxillin, Vimentin, Jagged-1 fragment, and Notch1 intracellular domain fragment also differed from those of control aorta.

Conclusions: This study provides the first description of the specific proteomic features of dilated pulmonary autograft tunica media, which separate them sharply not only from those of control pulmonary artery and aorta but also of aortic aneurysms. These findings suggest that dilated pulmonary autografts undergo a unique maladaptive remodeling process deserving further investigation. (J Thorac Cardiovasc Surg 2020;159:621-32)

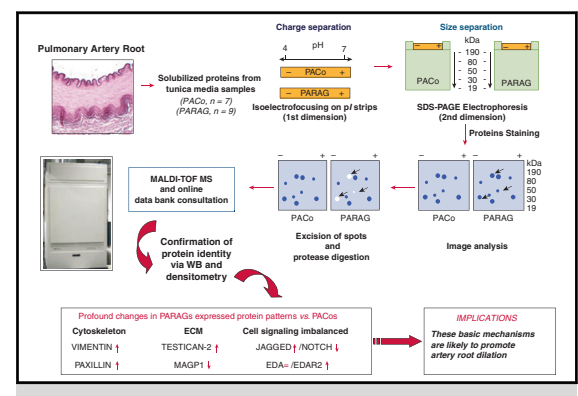

Illustration depicting the proteomic study of explanted pulmonary artery autograft roots.

\section{Central Message}

Dilated autograft roots show a pattern of extracellular matrix, intercellular signaling, and cell adhesion changes distinct from both normal pulmonary artery and normal ascending aorta.

\section{Perspective}

Pulmonary autograft roots dilating late after the Ross operation show maladaptive remodeling due to extracellular matrix, intercellular signaling, and cell adhesion changes translating into a phenotype quite distinct from that of normal aorta and of normal pulmonary artery. These findings may potentially impact indications for autograft root reoperation.

See Commentaries on pages 633 and 635.

\footnotetext{
From the ${ }^{\mathrm{a} H u m a n}$ Histology \& Embryology Unit and ${ }^{\mathrm{b}}$ Division of Cardiac Surgery, Department of Surgery, Dentistry, Pediatrics and Gynecology, Medical School, University of Verona, Verona, Italy.

This work was supported by FUR 2017-2018 funds from the Ministry of Education, University, and Research.

Drs Chiarini and Dal Prà contributed equally to this article.

Both senior authors (Drs Armato and Luciani) contributed equally to this article.

Received for publication Jan 30, 2019; revisions received June 26, 2019; accepted for publication July 2, 2019; available ahead of print Oct 1, 2019.

Address for reprints: Giovanni Battista Luciani, MD, Division of Cardiac Surgery, University of Verona, O. C. M. Piazzale Stefani 1, Verona, 37126, Italy (E-mail: giovanni.luciani@univr.it).

$0022-5223 / \$ 36.00$

Copyright (c) 2019 by The American Association for Thoracic Surgery

https://doi.org/10.1016/j.jtcvs.2019.07.083
}

The Ross operation uses a viable pulmonary autograft valve to replace the aortic one, making it an attractive therapy in children and young adults. ${ }^{1-3}$ However, after the Ross procedure, autograft root dilation with or without valve dysfunction is the main complication in late follow-up $\left(>8-10\right.$ years). ${ }^{4,5}$ Considering the resulting increased

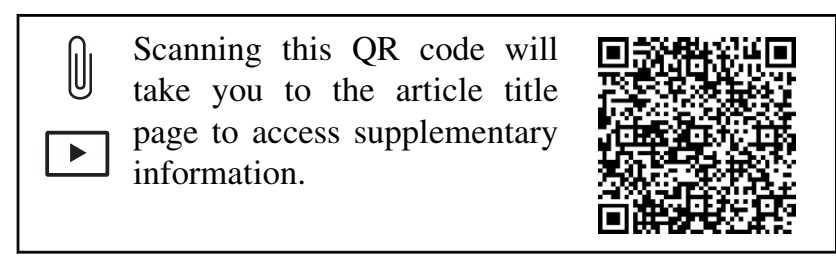




\begin{tabular}{|c|c|}
\hline \multicolumn{2}{|c|}{ Abbreviations and Acronyms } \\
\hline 2-DE & $\begin{aligned}= & 2 \text {-dimensional gel } \\
& \text { electrophoresis }\end{aligned}$ \\
\hline AA & $=$ ascending aorta \\
\hline$\alpha-\mathrm{SMA}$ & $=\alpha$-smooth muscle actin \\
\hline CTH & $=$ cystathionine $\gamma$-lyase \\
\hline ECM & $=$ extracellular matrix \\
\hline EDA & $=$ ectodysplasin \\
\hline EDAR & $=$ ectodysplasin receptor \\
\hline EDA2R & $=$ ectodysplasin -2 receptor \\
\hline JAG1 & $=$ Jagged -1 \\
\hline MAGP1 & $\begin{aligned}= & \text { microfibril-associated } \\
& \text { glycoprotein } 1\end{aligned}$ \\
\hline MALDI- & $\begin{aligned}= & \text { matrix-assisted-laser- } \\
& \text { desorption-ionization-time of } \\
& \text { flight/mass spectrometry }\end{aligned}$ \\
\hline NICD & $\begin{array}{l}=\text { Notch1 intracellular domain } \\
\text { fragment }\end{array}$ \\
\hline $\mathrm{PA}$ & $=$ pulmonary artery \\
\hline PMF & $=$ peptide mass fingerprinting \\
\hline PXN & $=$ paxillin \\
\hline SMC & $=$ smooth muscle cell \\
\hline TNF & $=$ tumor necrosis factor \\
\hline VIM & $=$ vimentin \\
\hline VSMC & $=$ vascular smooth muscle cells \\
\hline
\end{tabular}

morbidity due to reoperation on the autograft root, many institutions worldwide have questioned the indications and techniques of the Ross operation, particularly when performed in adult patients. ${ }^{6,7}$ Conversely, evidence from selected patient series indicated a satisfactory long-term clinical outcome and a durable autograft function. ${ }^{1,2,8,9}$ In 2 very recent studies with 20 years' follow-up after the Ross procedure, the risk of autograft reoperation ranged from $10 \%$ to $12 \%$ and of moderate aortic insufficiency from $13 \%$ to $19 \%$, but with a growing trend. ${ }^{1,2,9}$ Therefore, the controversy over the ability of the pulmonary autograft valve and root to adapt to systemic circulation and retain molecular and biomechanical viability continues to date. However, being coupled with lower mortality from all causes, the Ross procedure is still a better alternative than mechanical aortic valve replacement. ${ }^{10,11}$

Scant research evidence exists documenting structural and functional properties of the pulmonary artery (PA) root autografts once exposed to systemic circulation. Such either clinical (via echocardiography or magnetic resonance imaging) ${ }^{12-16}$ or experimental ${ }^{17-19}$ information only concerns pulmonary autograft root biomechanics. Histologic and immunohistochemical analysis of pulmonary autograft tissues explanted from reoperated or deceased patients has provided additional insights. ${ }^{19}$
Some authors suggested adaptive remodeling occurs in pulmonary autograft valves. ${ }^{20,21}$ Others speculated progressive dilation may be due to failed autograft vascular wall (root) remodeling. ${ }^{19}$ This issue has also relevant implications for a panoply of complex congenital heart defects, where surgical repair (ie, arterial switch, Damus-Kaye-Stansel, and Norwood operations) uses the native PA as neo-aortic root. $^{20}$

Recently, proteomic studies elucidated molecular mechanisms of aortic aneurysm formation in syndromic (ie, Marfan) and non-syndromic patients. ${ }^{22-24}$ Conversely, no proteomic data were available about aneurysmal PA autografts. The hypothesis of the present study is that aneurysmal PA autograft may present a proteomic profile distinct from normal PA and normal aortic root tissue, thereby expressing a form of maladaptive remodeling after prolonged exposure to systemic circulation. Therefore, we investigated the proteome differences between the tunica media of PA autografts exposed to systemic circulation for 8 to 16 years and control PA samples. Furthermore, the proteome of ascending aorta (AA) control samples was compared with pulmonary autograft to assess whether any aortic-like remodeling occurs in PA autografts.

\section{METHODS}

\section{Source of Tissue}

The institutional review board approved the present study and waived the need for patient consent. Between May 1994 and April 2018, 140 consecutive patients, 116 male and 24 female, aged $25.9 \pm 19.7$ years (0.08-49 years), underwent the Ross operation. During the original operation, the pulmonary autograft was implanted by placing the nonfacing (anterior) sinus of Valsalva in the noncoronary sinus position. All consecutive patients undergoing pulmonary autograft root reoperation after August 2008 were prospectively enrolled in this study. Twenty (14\%) of 138 late survivors required autograft root reoperation during a 24-year follow-up. Indication for autograft root reoperation was based on morphometric criteria (Svensson ratio) gathered at follow-up echocardiographic examinations regardless of valve dysfunction severity. ${ }^{25}$

Before reoperation, patients underwent cardiac magnetic resonance imaging. Pulmonary autograft tissue samples were collected from the noncoronary sinus of Valsalva. During the study period, 7 cardiac donors, with no remarkable echocardiographic and intraoperative findings, were used as healthy controls. From them, control PA from the nonfacing sinus of Valsalva and thoracic AA control samples were collected. Soon after retrieval, in the operating room PA and AA tissues were washed 5 times (5 minutes each) with sterile cold phosphate-buffered saline then, after a short incubation (10 minutes) in collagenase type II solution ( $1.42 \mathrm{mg} / \mathrm{mL}$; Sigma, Milan, Italy) they were dissected into tunicae adventitia, media, and intima onto a laboratory table using a magnification lens. Here, we report the proteomic results from the tunica media samples.

\section{Tissue Sample Processing and Proteomic and \\ Statistical Analyses}

To elucidate the molecular mechanisms underlying pulmonary autograft remodeling and dilation, we investigated differences in PA tunica media protein expression patterns. To improve final spot resolution and detect low-abundance proteins, the patients' protein lysates were separated into $5 \mathrm{p} I$ sets, ie, $\mathrm{p} I 3.0$ to $4.6, \mathrm{p} I 4.5$ to $5.5, \mathrm{p} I 5.3$ to $6.3, \mathrm{p} I 6.2$ to 7.0 , and $\mathrm{p} I 7.0$ to 10.0 , before carrying out 2-dimensional electrophoresis 
(2-DE), matrix-assisted-laser-desorption-ionization-time of flight/mass spectrometry (MALDI-TOF/MS), peptide mass fingerprinting (PMF), and bioinformatic analysis (Figure 1).

For the descriptive statistical analysis, Welch's analysis of variance with post hoc Dunnet's test (all pairwise multiple comparison procedures) was applied to the data and a $P<.05$ was considered as statistically significant. However, if the variances resulted significantly different by Bartlett test, groups were compared using the one-way nonparametric analysis of variance Kruskal-Wallis test with Steel-Dwass-Critchlow-Fligner test for the statistical comparisons. Student $t$ test was used when only 2 independent groups (PA control samples and pulmonary autografts) were compared.

A more detailed description of the methods herein used, ie, 2-DE, MALDI-TOF/MS, PMF, bioinformatics (Swiss Prot database), Western immunoblotting, and statistical analysis is given in the Appendix E1.

\section{RESULTS}

\section{Patient Characteristics}

During the study period, 9 patients, mean age $25.0 \pm 11.6$ years (6-43 years) underwent after an average of $12 \pm 3$ years (8-16 years) reoperation for autograft root dilation. This population represents one-half $(9 / 17,53 \%)$ of all patients who have undergone Ross reoperation at our institution and all consecutive patients seen since 2008 (Table 1). These data were comparable with those of the overall Ross root reoperation population (age at Ross: $24 \pm 11$ years; interval to reoperation: $9 \pm 3$ years). Original indications to Ross operation were native aortic valve insufficiency in 8 patients $(89 \%)$ and mixed lesions in 1 , similar to indications in the overall Ross reoperation population (aortic insufficiency, 17/20 patients, 85\%). In addition, 7 (78\%) presented with bicuspid valve at original Ross surgery (16/20, $80 \%$ in overall redo population). Finally, the original Ross technique was root replacement in all 9 patients in this study (compared with 17/20, 85\% in the overall population). Therefore, these patients constitute a highly representative sample of all patients undergoing surgical reintervention for pulmonary autograft dilation at our Center. When compared with age- and

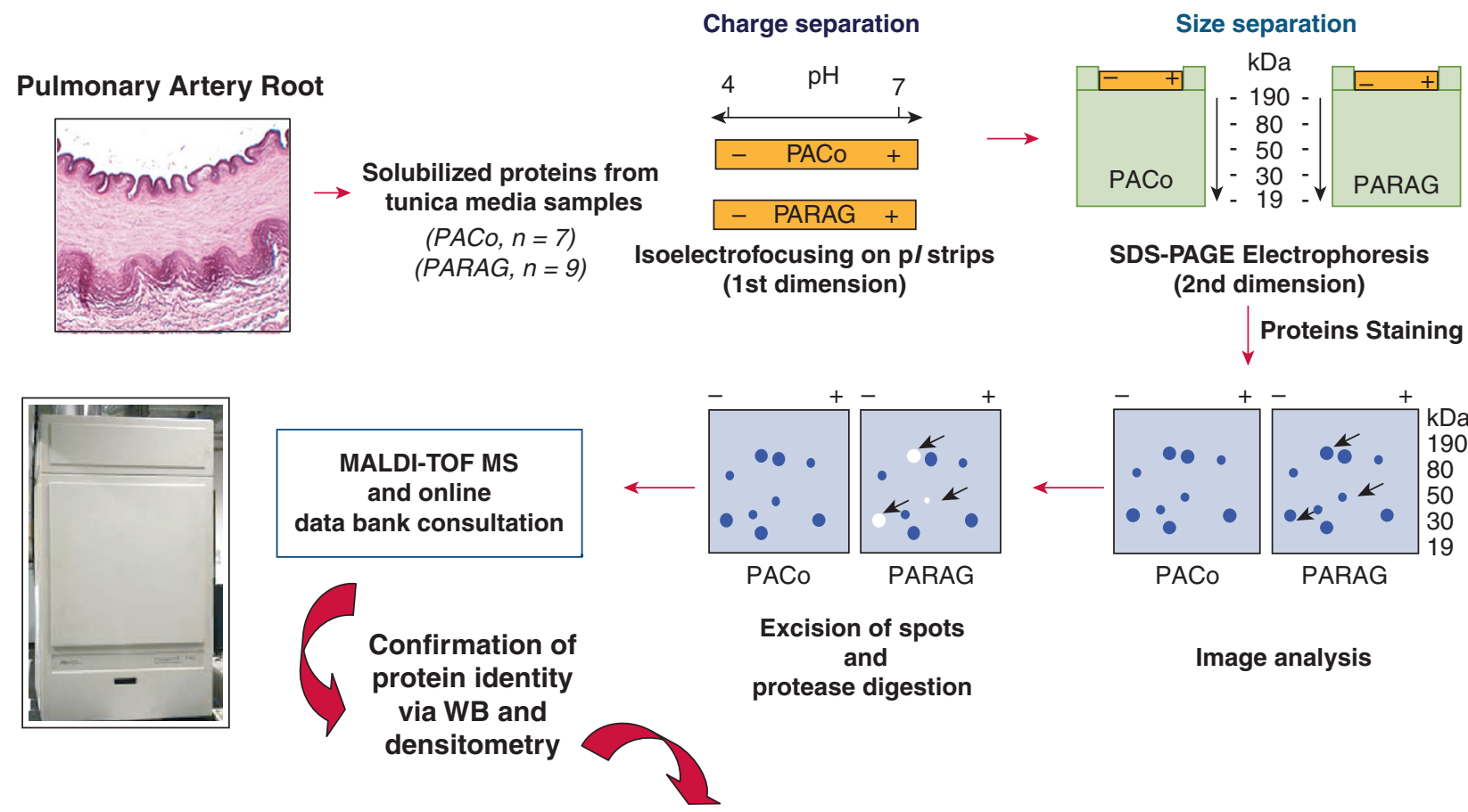

\begin{tabular}{|c|c|c|c|c|}
\hline \multicolumn{3}{|c|}{ Profound changes in PARAGs expressed protein patterns vs. PACos } & \multirow{3}{*}{$\longrightarrow$} & \multirow{3}{*}{$\begin{array}{l}\quad \text { IMPLICATIONS } \\
\text { These basic mechanisms } \\
\text { are likely to promote } \\
\text { artery root dilation }\end{array}$} \\
\hline Cytoskeleton & ECM & Cell signaling imbalanced & & \\
\hline $\begin{array}{l}\text { VIMENTIN } \uparrow \\
\text { PAXILLIN } \uparrow\end{array}$ & $\begin{array}{c}\text { TESTICAN-2 } \uparrow \\
\text { MAGP } 1 \downarrow\end{array}$ & $\begin{array}{c}\text { JAGGED } \uparrow / \text { NOTCH } \downarrow \\
\text { EDA }=/ \text { EDAR2 } \uparrow\end{array}$ & & \\
\hline
\end{tabular}

FIGURE 1. A proteomic comparative study of tunica media isolated from pulmonary artery control samples (PACos) and pulmonary artery root autograft samples (PARAGs) exposed to systemic circulation. Protein contents were analyzed by means of proteomic methods that allowed us to separate the proteins according to their isoeletric point (charge separation) and next according their mass (size separation) via 2-dimensional electrophoresis. The identity of each protein spot was assessed via matrix-assisted-laser-desorption-ionization-time of flight/mass spectrometry (MALDI-TOF/MS). The identified proteins were confirmed and quantified via Western immunoblotting $(W B)$. The results revealed striking differences between the proteomes of PARAGs and PACos. pI, Isoelectric point; SDS-PAGE, sodium dodecyl sulfate polyacrylamide gel electrophoresis; $M A G P 1$, Microfibril-associated glycoprotein1; EDA, ectodyspla$\sin ; E D A R$, ectodysplasin receptor. 
TABLE 1. Demographics of patients undergoing Ross and control individuals

\begin{tabular}{lccc}
\hline \multicolumn{1}{c}{ Variable } & $\begin{array}{c}\text { Control } \\
\text { subjects }\end{array}$ & $\begin{array}{c}\text { Ross } \\
\text { patients }\end{array}$ & $\begin{array}{c}\boldsymbol{P} \\
\text { value }\end{array}$ \\
\hline $\mathrm{N}$ & 7 & 9 & \\
Male sex & $5(71 \%)$ & $7(78 \%)$ & $.8^{*}$ \\
\hline Mean age, y & $39 \pm 12$ & $37 \pm 14$ & $.6 \dagger$ \\
Range, y & $22-58$ & $15-51$ & \\
Mean height, cm & $169.0 \pm 9.5$ & $171.0 \pm 7.5$ & $.7 \dagger$ \\
Range, cm & $155-178$ & $158-182$ & \\
Mean body weight, kg & $69.0 \pm 10.4$ & $66.0 \pm 9.3$ & $.7 \dagger$ \\
Range, kg & $55-81$ & $54-76$ & \\
Mean age at Ross, y & & $25 \pm 12$ & \\
Range, y & & $6-43$ & \\
Mean interval & & $12 \pm 3$ & \\
$\quad$ to reoperation, y & & $8-16$ & \\
Range, y & & & \\
Mean aortic root $\varnothing$ & & $5.2 \pm 0.4$ & \\
$\quad$ at reoperation, cm & & $4.5-5.8$ & \\
Range, cm & & & \\
\hline
\end{tabular}

Values are mean \pm standard error of the mean. *Pearson $\chi^{2}$ test. $\dagger$ Student $t$ test.

sex-matched PA control subjects, no significant difference obtained in terms of any demographic variable (Table 1). Ross autograft root reoperation consisted in root replacement with valve preservation in 5 patients (Video 1) and composite valve and root replacement in the remaining 4. All patients survived reoperation and are in satisfactory clinical conditions at a mean follow-up of 9.2 years (range 7.6-10.8 years).

\section{2-DE Analysis of PA Tunica Media Protein Lysates}

A substantial number of soluble proteins, ie, 33 spots in the 2-DE gels, could be separated from the 4.5 to 5.5 and 5.3 to $6.3 \mathrm{p} I$ range samples. Therefore, the present study focused on the latter $2 \mathrm{p} I$ ranges.

The 2-DE overlapping patterns of tunica media proteins from the 4.5 to 5.5 and 5.3 to $6.3 \mathrm{p} I$ range of PA control samples and autograft root lysates are displayed in Figure E1. By gel matching with DECODON software (DECODON, Greifswald, Germany), 33 spots whose expression intensities differed (some by even 2-fold) between the PA control samples and autograft root groups were selected, excised, subjected to in-gel tryptic digestion, and analyzed via MALDI-TOF/MS, PMF, and online bioinformatics. Among the proteins thus putatively identified, we initially focused on 8 proteins that also play significant roles in sporadic nonsyndromic AA aneurysms. ${ }^{23,24}$ Such proteins and their features (index codes, peptide sequence coverage, total Molecular Weight Search scores, and theoretical/in-gel pIs and $\mathrm{M}_{\mathrm{r}}$ values) are listed in Table 2. They belonged to 4 classes: (1) cytoskeleton and cell adhesion; (2) extracellular matrix (ECM); (3) enzyme; and (4) cell signaling.

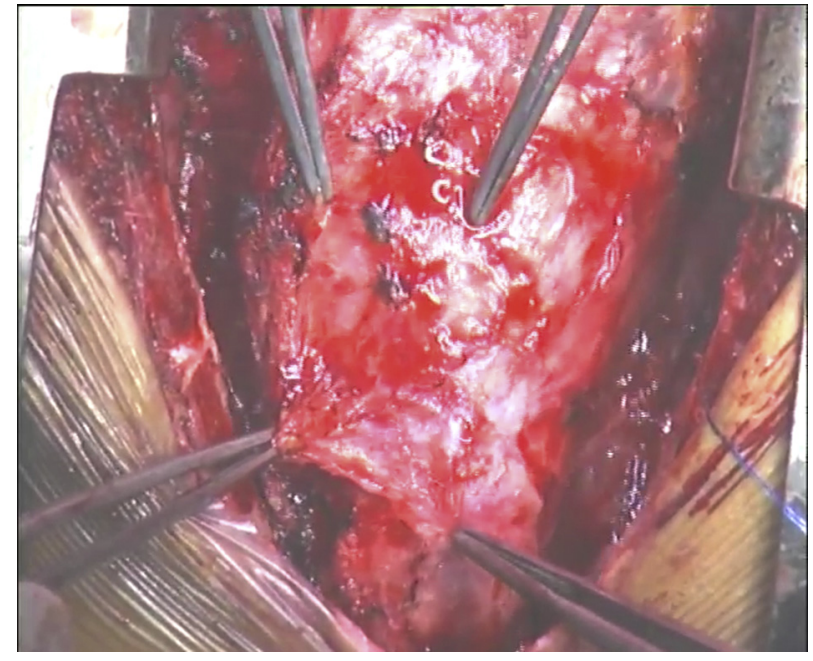

VIDEO 1. Valve-preserving autograft root replacement, using the root remodeling technique (ie, Yacoub operation) in a patient presenting with autograft root aneurysm 12 years after original Ross operation, using the free-standing root technique. The dense adhesions of the root aneurysm to the inner sternal table requiring careful chest reentry are evident. The pathologic findings include severe autograft root dilation, clearly distinct from the native ascending aortic wall, and marked cephalad dislocation of the right coronary button, in contrast with the grossly unremarkable aspect of the autograft valve leaflets. Video available at: https://www.jtcvs.org/article/S0022-5223(19)31634-4/fulltext.

\section{Immunoblotting Validation of Protein Identification}

To confirm protein identification and establish differential protein expression, immunoblotting analysis was performed on the same PA control samples, Ross pulmonary autografts, and AA control samples tunica media lysates as also used for proteomic analyses.

Cytoskeleton and cell adhesion. Vimentin (VIM) is the predominant constituent of intermediate-size filaments in vascular smooth muscle cells (VSMCs). ${ }^{26}$ Immunoblotting revealed that VIM levels were greater in Ross autografts than in PA control samples protein lysates $(+170 \%$; $P<.0001$ ) (Figure 2, A).

Paxillin (PXN) protein abounds in focal adhesions, acting as a discrete transmembrane link between cytoskeletal actin filaments and ECM. Importantly, PXN also regulates actin filament dynamics and organization during smooth muscle cell (SMC) contraction. ${ }^{27} \mathrm{PXN}$ native holoprotein (62-kDa) was up-regulated $(+125 \%, P<.0001)$ (Figure $2, B)$ in Ross autografts versus PA control samples immunoblots. PXN $55-\mathrm{kDa}$ proteolytic fragment was exclusively observed in autografts lysates (Figure 2, B).

Conversely, the levels of $42-\mathrm{kDa} \alpha$-smooth muscle actin ( $\alpha$-SMA) holoprotein-a myofibroblast marker predominating in vascular (V)SMCs with a contractile phenotype $^{26}$-were rather alike $(P=.980)$ in both PA control samples and autografts lysates (Figure 2, $C$ ). Moreover, no $\alpha$-SMA proteolytic fragments were detected 
TABLE 2. Immunoblot-validated proteins identified via MALDI-TOF/MS, PMF, and online bioinformatics that are differentially expressed in tunica media from Ross pulmonary autografts and PA control samples

\begin{tabular}{|c|c|c|c|c|c|c|c|}
\hline No. & Protein & $\begin{array}{c}\text { SwissProt } \\
\text { accession no. }\end{array}$ & $\begin{array}{l}\text { MOWSE } \\
\text { score }\end{array}$ & $\begin{array}{c}\% \\
\text { Coverage }\end{array}$ & $\begin{array}{l}\text { Theoretical } \\
\mathbf{p I} / \mathrm{M}_{\mathbf{r}} \text { (Da) }\end{array}$ & $\begin{array}{c}\text { Observed } \\
\mathrm{pI} / \mathbf{M}_{\mathbf{r}}(\mathrm{Da})\end{array}$ & Protein function \\
\hline 1 & VIM & P08670 & $6.56 \mathrm{E}+9$ & 77.4 & $5.06 / 53,651$ & $5.2 / 51,740$ & $\begin{array}{l}\text { Cytoskeletal intermediate } \\
\text { filaments }\end{array}$ \\
\hline 2 & PXN & P49023 & 656400 & 56 & $5.73 / 64,533$ & $5.8 / 64,300$ & $\begin{array}{l}\text { FAs attachment to ECM } \\
\text { and } \mathrm{pp} 121^{\mathrm{FAK}} \text { signaling }\end{array}$ \\
\hline 3 & MAGP1 & P55001 & 36850 & 41 & $4.86 / 20,826$ & $4.8 / 20,300$ & $\begin{array}{l}\text { Component of elastin- } \\
\text { associated microfibrils }\end{array}$ \\
\hline 4 & Testican2 & Q92563 & $3.03 \mathrm{E}+09$ & 68.5 & $4.71 / 46,779$ & $4.75 / 46,100$ & $\begin{array}{l}\text { ECM organization, } \\
\text { MT-MMP disinhibition }\end{array}$ \\
\hline 5 & $\mathrm{CTH}$ & P32929 & 71728 & 61 & $6.21 / 44,508$ & $6.1 / 43,800$ & $\mathrm{H}_{2} \mathrm{~S}$-producing lyase \\
\hline 6 & $\begin{array}{l}\text { Soluble JAG1 } \\
\text { fragment }\end{array}$ & Q99740 & 199,922 & 52.9 & $6.17 / 28,405$ & $6.1 / 29,030$ & Notch1 ligand \\
\hline 7 & EDA2R & Q9HAV5 & $3.16 \mathrm{E}+08$ & 29 & $4.91 / 32,729$ & $4.7 / 33,350$ & TNF-like receptor activity \\
\hline
\end{tabular}

MOWSE, MOlecular Weight SEarch; $p I$; isoeletric point; $M_{r}$, relative mass; Da, Dalton; VIM, vimentin; PXN, paxillin; FAs, focal adhesions; ECM, extracellular matrix; FAK, focal adhesion kinase; $M A G P 1$, microfibril-associated glycoprotein 1; MT-MMP, membrane-type matrix metalloproteinase; $C T H$, cystathionine $\gamma$-lyase; JAG1, Jagged-1; EDA2R, ectodysplasin-2 receptor; $T N F$, tumor necrosis factor.

in both PA control samples and autografts lysates (not shown).

Extracellular matrix. Microfibril-associated glycoprotein1 (MAGP1), encoded by MFAP2 gene, is an ECM component of the 10- to $12-\mathrm{nm}$ microfibrils surrounding the elastic fibers' elastin core. ${ }^{28}$ In Ross autografts, MAGP1 protein was down-regulated $(-43 \%, P<.0001)$ versus PA control samples lysates (Figure $3, A$ ).

However, testican-2 levels, a proteoglycan encoded by SPOCK2 gene negatively regulating ECM metalloprotease activity, were increased $(+41 \%, P<.0001)$ in Ross autografts versus PA control samples lysates (Figure 3, B). Enzyme. Cystathionine $\gamma$-lyase (CTH; EC4.4.1.1) cleaves cysteine to produce $\mathrm{H}_{2} \mathrm{~S}$, an endogenous signaling molecule in vascular tissues partaking in blood pressure regulation ${ }^{29}$ and, when in excess, promoting apoptosis. ${ }^{23}$ However, CTH 42-kDa protein isoform levels did not differ $(P=.085)$ in Ross pulmonary autografts versus PA control samples lysates (Figure 3, C).

Cell signaling. Jagged1 holoprotein (JAG1, 172-kDa) is a Notch receptor ligand involved in the mediation of Notch signaling. It can undergo intramembrane proteolysis, giving rise to a soluble extracellular ligand (sJAG1, 42-kDa). ${ }^{30}$ This proteolytic fragment abounded more $(>10$-fold, $P<.0001)$ in Ross autografts than in PA control samples lysates (Figure 4, A), whereas JAG1 holoprotein was undetectable in either kind of lysates (not shown).

These results suggested that we also should investigate the JAG1.s receptor, ${ }^{30}$ ie, Notch1 protein, even though its $\mathrm{p} I$ was not within the chosen $\mathrm{p} I$ ranges (4.5-5.5 and 5.36.3). Thus, Notch1 holoprotein was very weakly expressed in PA control samples lysates, whereas it was absent in autografts lysates (not shown). However, Notch1 active intracellular cytoplasmic domain (NCID), ${ }^{31}$ which was detectable on immunoblots, was down-regulated $(-58 \%$, $P<.0001)$ in pulmonary autografts versus PA control samples lysates (Figure 4, B).

Finally, immunoblotting demonstrated that ectodysplasin2 receptor (EDA2R), a tumor necrosis factor (TNF) receptor family member, was up-regulated $(+180 \%, P<.0028)$ in Ross autografts versus PA control samples lysates (Figure 4, C). However, the levels of EDA2R's ligand, ectodysplasin (EDA), were alike in both groups $(P=.939$, Figure $4, D)$. Notably, the $\mathrm{p} I$ of EDA also was not within the $\mathrm{p} I$ ranges initially considered.

\section{PA Versus AA Control Samples Tunica Media Protein Expression}

Cytoskeleton and cell adhesion. In AA control samples, VIM levels were greater $(+115 \% ; P<.0001)$ than in PA control samples (Figure 2, $A$ ). Conversely, PXN holoprotein (62-kDa) was similarly expressed $(P=.89)$ in both AA control samples and PA control samples (Figure 2, B). PXN 55-kDa fragment was exclusively expressed in AA control sample lysates (Figure 2,B). Finally, the amount of $\alpha$-SMA was similar $(P=.2)$ in both AA control samples and PA control samples (Figure 2, C).

Extracellular matrix. MAGP1 protein was expressed more weakly $(-68 \%, P<.0001)$ in AA control samples than in PA control samples (Figure 3, A). Conversely, testican-2 expression was alike in AA control samples and PA control samples $(P=.93$, Figure $3, B)$.

Enzyme. The levels of $42-\mathrm{kDa}$ CTH isoform were slightly increased in AA versus PA control samples $(P<.0001$, Figure 3, C). 
VIM
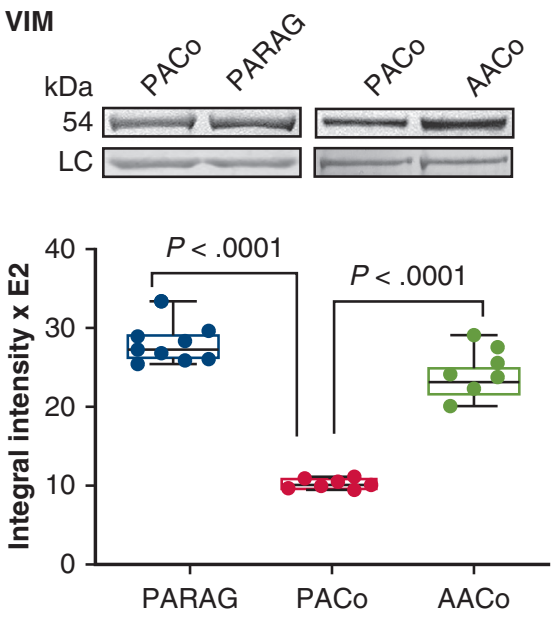

A

PXN
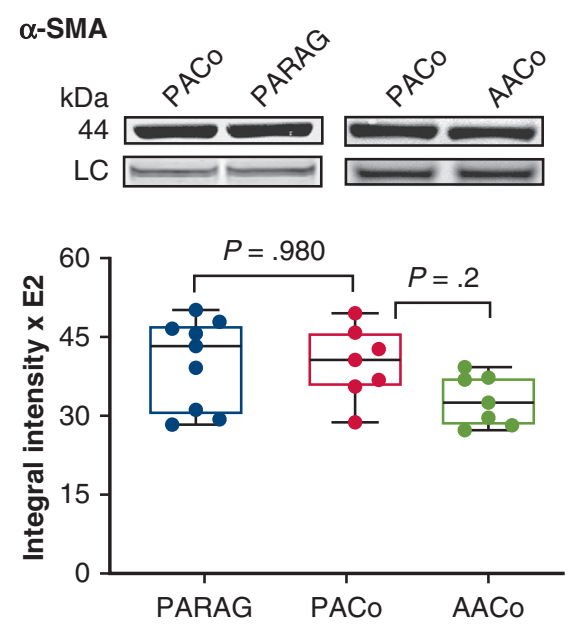

C

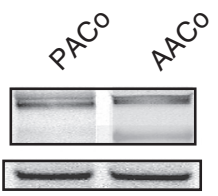

$55 \mathrm{kDa}$
$62 \mathrm{kDa}$

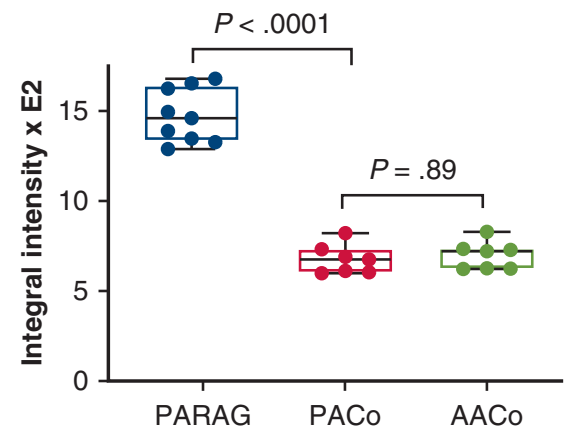

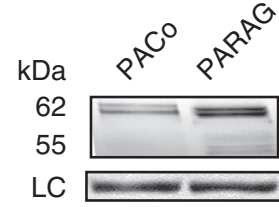

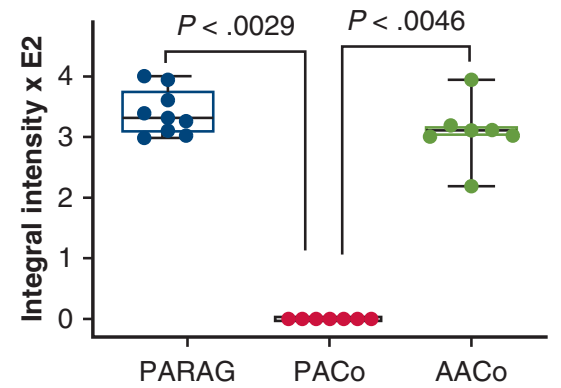

FIGURE 2. The different expression of A, vimentin (VIM), B, paxillin (PXN), and C, $\alpha$-smooth muscle actin $(\alpha$-SMA) of the pulmonary artery root autograft (PARAG, blue dots) vs pulmonary artery control (PACos, red dots) and ascending aorta control (AACo, green dots). The protein extract samples were run on sodium dodecyl sulfate polyacrylamide gel electrophoresis and blotted as detailed in the Methods section (Appendix E1). The results were gained via immunoblotting plus densitometric assessment (integral intensity $\times \mathrm{E} 2)$ of the specific bands on whole sets of samples. The loading control $(L C)$ protein is Lamin B. A, VIM expression was up-regulated both in PARAGs and AACo vs. PACos cases. B, PXN holoprotein (62-kDa) expression was increased in PARAGs vs PACos and AACo cases. PXN fragment (55-kDa) was instead detected only in pulmonary autografts and AACo cases. C, $\alpha$-SMA protein contents were alike in the 3 groups. The data are shown as dot plots of each protein specific band densitometry values. The lower and upper borders of the box represent the first and the third quartiles, with the median indicated by a black transverse line, and the minimum and maximum values are shown as whiskers with end caps. $P$ values indicate comparisons of PARAGs vs PACos or AACo vs PA control samples respectively (statistical analysis. VIM, PXN-62-kDa, $\alpha$-SMA: Welch analysis of variance with Dunnet's test for multiple comparisons; PXN fragment 55-kDa: Kruskal-Wallis test with Steel-Dwass-Critchlow-Fligner test for all pairs comparisons).

Cell signaling. JAG1 holoprotein (172-kDa) was undetectable in PA control samples, at sharp variance with its expression in AA control samples (data not shown). Conversely, the weak expression of extracellular soluble 42-kDa JAG1 fragment in PA control samples contrasted with its total lack of expression in AA control samples (Figure 4, A).

Notably, expression of Notch1, JAG1's receptor, exhibited entirely different patterns in AA versus PA control samples (Figure 4, B). At variance with previous findings 
MAGP1

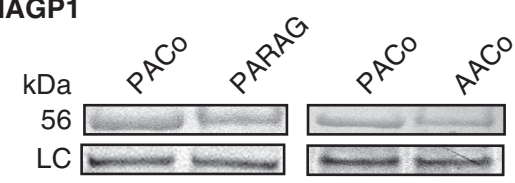

A

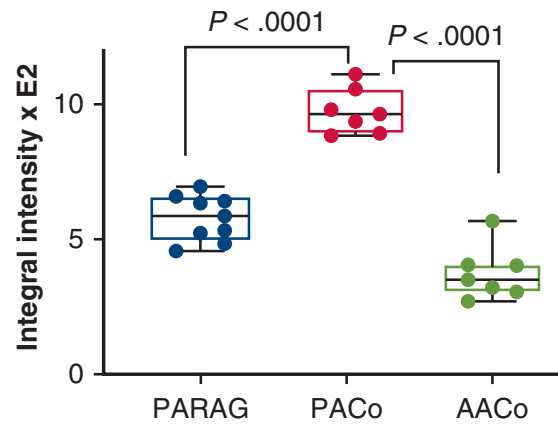

CTH
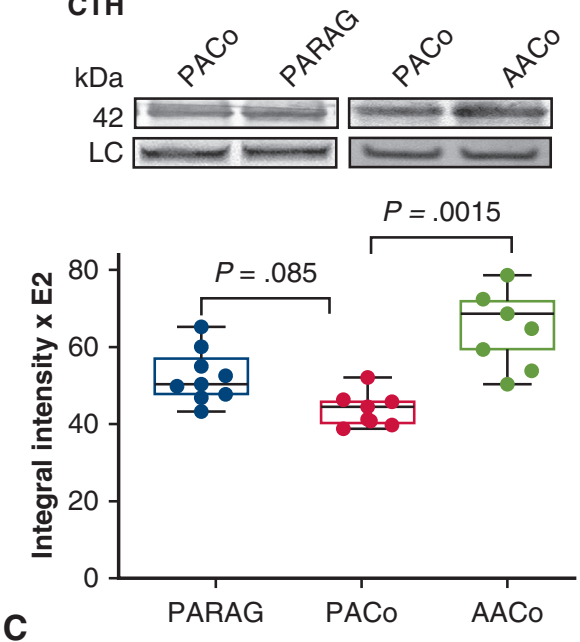

Testican-2
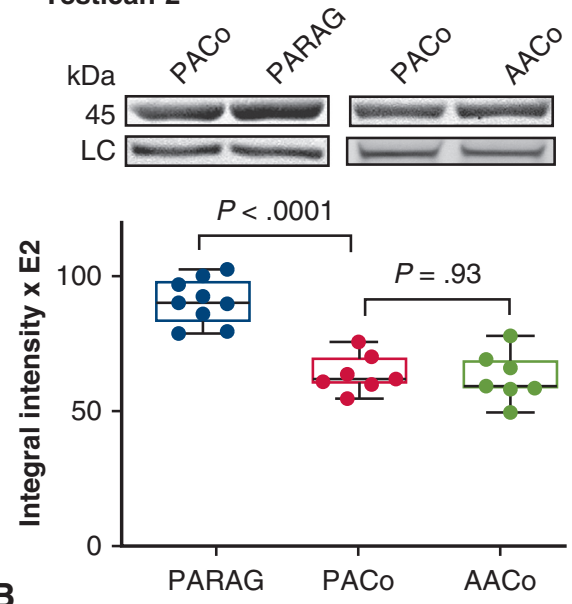

FIGURE 3. The different expression of A, microfibril-associated glycoprotein1 (MAGP1), B, testican-2, and C, cystathionine $\gamma$-lyase $(C T H)$ of the pulmonary artery root autograft (PARAGs, blue dots) vs pulmonary artery control (PACos, red dots) and ascending aorta control (AACo, green dots). The protein extract samples were run on sodium dodecyl sulfate polyacrylamide gel electrophoresis and blotted as detailed in the Methods section (see Appendix E1). The results were gained via immunoblotting plus densitometric assessment (integral intensity $\times$ E2) of the specific bands on whole sets of samples. The loading control $(L C)$ protein is Lamin B. A, MAGP1 was down-regulated in both PARAGs and AACo vs PACos cases. B, Testican-2 levels were increased in PARAGs vs PACos and AACo samples. C, The levels of 42-kDa CTH protein isoform were alike in PARAG vs PACo groups, but, conversely, were slightly increased in AACo vs PACo samples. The data are shown as dot plots of each protein-specific band densitometry values. The lower and upper borders of the box represent the first and the third quartiles, with the median indicated by a black transverse line, and the minimum and maximum values as whiskers with end caps. $P$ values indicate comparisons of PARAG vs PACo or AACo vs PACo samples respectively (statistical analysis. Welch's analysis of variance with Dunnet's test for multiple comparisons in all instances shown).

with AA control samples, in which only Notch1 holoprotein, but no fragment, was detectable, ${ }^{23}$ Notch1 holoprotein was quite faint (not shown), whereas its Notch1 intracellular domain (NICD) fragment (64-kDa) was clearly visible in PA control samples lysates (Figure 4, B). Finally, the expression levels of EDA2R and its ligand, EDA, were equivalent in AA and PA control samples (Figure 4, $C$ and $D$ ).

\section{DISCUSSION}

In the present work, we identified significant differences in protein expression occurring in the media of pulmonary autograft roots compared with PA control samples and with AA control sample lysates. To the best of our knowledge, this is the first study aimed at identifying through a proteomic approach specific pathologic processes 

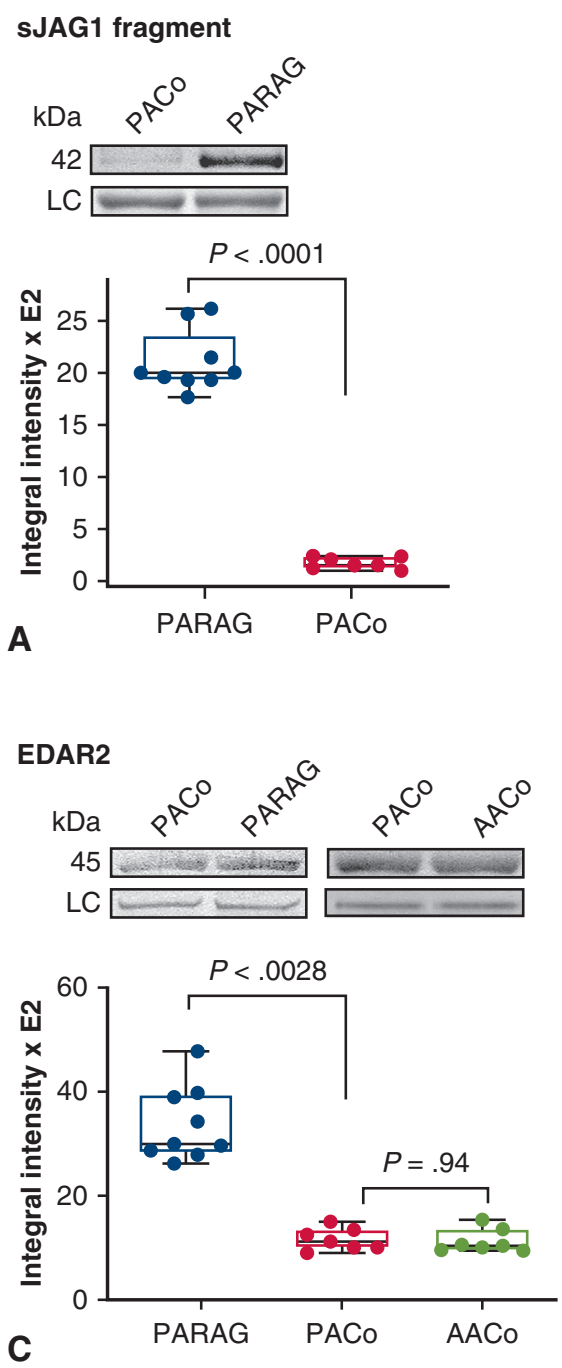

NICD
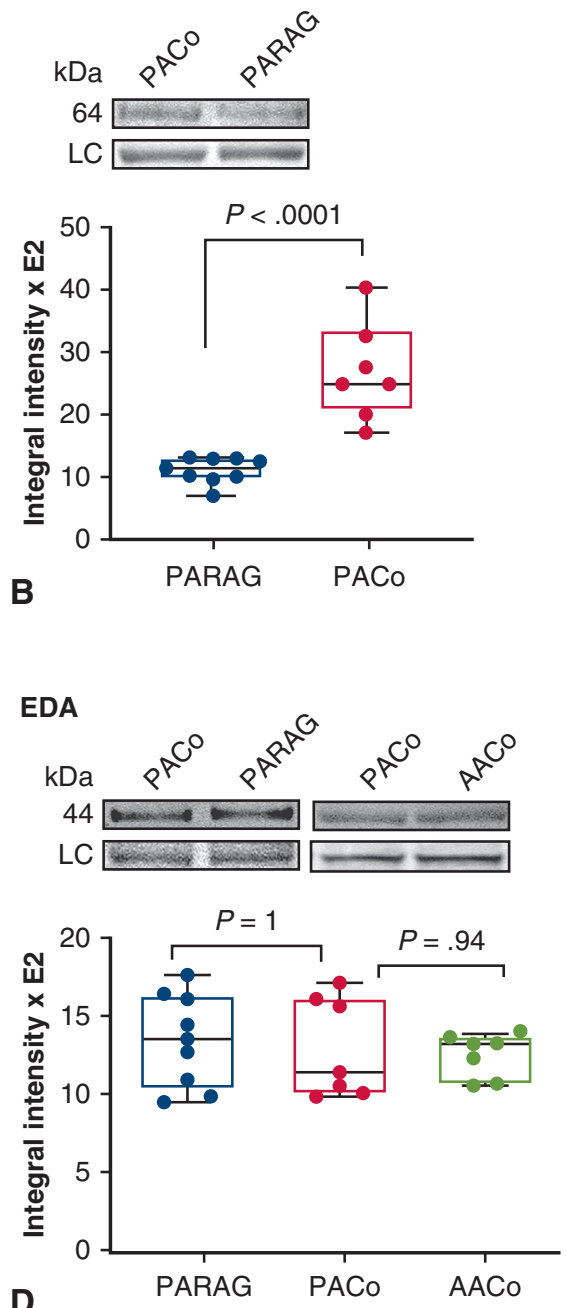

FIGURE 4. Changes in 4 different cell signaling-related proteins in pulmonary artery root autografts (PARAG, blue dots) vs pulmonary artery controls (PACo, red dots) and ascending aorta controls (AACo, green dots). The tunica media protein lysates samples were run on sodium dodecyl sulfate polyacrylamide gel electrophoresis and blotted as detailed in the Methods section (Appendix E1). Whole sets of samples were analyzed via immunoblotting plus densitometry of the specific bands. The loading control $(L C)$ protein is Lamin B. A, The level of soluble-Jagged-1 (sJAG1) fragment increased in PARAG vs PACo samples, whereas in AACo samples JAG1 was undetectable. B, Notch1 intracellular domain fragment (NICD) expression was down-regulated in PARAG vs PACo samples. Conversely, in AACo lysates, NICD was undetectable. C, Ectodysplasin receptor (EDA2R) expression was up-regulated in PARAG vs PACo and AACo samples. D, Ectodysplasin $(E D A)$ protein levels were alike $(P>.05)$ in the 3 groups. Bars are means \pm standard errors of the mean.. The data are shown as dot plots of each protein-specific band densitometry values. The lower and upper borders of the box represent the first and the third quartiles, with the median indicated by a black transverse line, and the minimum and maximum values as whiskers with end caps. $P$ values indicate comparison of PARAG vs PACo or AACo vs PACo samples respectively (Statistical analysis. sJAG1, NICD: Student $t$ test; EDAR2, EDA: Welch analysis of variance with Steel test for multiple comparisons).

occurring in late (8-16 years after the Ross procedure) reoperated autografts. The identification of protein alterations by means of the proteomic methods depicted in the Figure 1 is crucial for revealing the molecular mechanism(s) operating in the neoaortic root of patients with autograft dilation. The specific proteomic work-flow applied for identifying and profiling proteins in tunica media tissue samples involves protein separation according to isoelectric point $(\mathrm{p} I)$ and relative mass $\left(\mathrm{M}_{\mathrm{r}}\right)$, trypsin digestion, MALDI-TOF/MS analysis, bioinformatic database searches, and Western immunoblotting validation for quantitative profiling of proteins (Figure 1). Here, we discuss our results considering each of the identified and validated proteins.

\section{Vimentin}

The intermediate filament protein VIM is an integral part of the cytoskeleton of VSMCs. Our comparative analysis 
revealed substantial differences in VIM expression among PA control samples, Ross autografts, and AA control sample lysates. In particular, VIM expression is weak in PA control samples, being instead stronger in autografts and AA control samples. VIM is among the biomolecules that regulate VSMCs migration, contraction, and also vascular remodeling whose alteration is a key feature of vessel diseases. ${ }^{32}$ Schiffers and colleagues ${ }^{33}$ provided the first evidence that VIM modulates arterial structural responses to blood flow changes thus expanding from acute vasomotor responses to chronic arterial wall remodeling the role of VIM in the mechano-transduction of shear stress. Notably, VSMCs have the ability (plasticity) to switch from a quiescent contractile phenotype to a secretory, proliferating, migratory, apoptosis-prone phenotype coupled with ECM remodeling. ${ }^{34}$ The increased expression of VIM is a marker of a SMCs' synthetic/de-differentiated phenotype, which also associates with vascular injury.

\section{Paxillin}

Cell adhesion, migration, and proliferation are crucial features of vascular remodeling. PXN is the main component of focal adhesions acting as a multidomain scaffold/adapter protein that coordinates signaling events downstream of integrins-ECM links. By recruiting structural and regulatory proteins, PXN determines dynamic changes in cytoskeletal organization, actin polymerization, and gene expression, which are necessary for cell adhesion, migration, and survival. ${ }^{35}$ Moreover, Veith and colleagues ${ }^{35}$ identified PXN as a new regulator protein promoting human PA's remodeling and SMCs growth.

Our findings revealed that PXN is more highly expressed in PA control samples than AA control samples for reasons presently not understood. An even more heightened expression of $62-\mathrm{kDa}$ PXN holoprotein and of its $55-\mathrm{kDa}$ fragment occurs in the dilated tunica media of both Ross autografts and of non-syndromic thoracic AA aneurysms. ${ }^{24}$ Such increases in PXN expression might cause an abnormal actin cytoskeleton remodeling favoring a progressive vascular wall dilation.

\section{$\alpha$-Smooth Muscle Actin}

$\alpha$-SMA is both a cell type-specific isoform and the most abundant component $(70 \%)$ of total actin in adult VSMCs. ${ }^{26}$ Our results showed that $\alpha$-SMA holoprotein expression (with no cleavage) is similar in PA control samples, autografts, and AA control sample lysates (Figure 2, C). Conversely, an increased $\alpha$-SMA proteolysis was observed in non-syndromic thoracic AA aneurysms. ${ }^{23}$ An increased $\alpha$-SMA expression occurred 10 months after Ross operation in porcine autografts placed in the aortic position. ${ }^{18}$ Interestingly, a down-regulation of SMCs markers in the PA media was observed in cases (aged 1 day to 9 months) of transposition of the great arteries. ${ }^{22}$
The causes of such discrepancies are not known. Clearly, the loss of coordination among cytoskeletal components like VIM, PXN, and $\alpha$-SMA proper of non-syndromic thoracic aorta aneurysms ${ }^{23,24}$ is only partially replicated in the maladpted autografts.

\section{MAGP1}

Significantly lower amounts of MAGP-1 were expressed in Ross autografts than in PA control samples. Together with fibrillin-1, MAGP-1 is the major components of vascular microfibrils both postnatally and into adulthood. In AA control samples, the amount of MAGP-1 is lesser than in PA control samples and also strongly decreases in non-syndromic thoracic AA aneurysms. ${ }^{24}$ Notably, loss-of-function mutations of MAGP-2 contribute to familial thoracic AA aneurysms and dissections. ${ }^{36}$ It is known that MAGP-1 knockdown in zebrafish results in many vascular defects suggesting that MAGP-1 is required for the structural integrity of the vessel walls. Similar changes in vascular phenotype also occurred in the mouse after inactivation of both MAGP-1 and MAGP-2, revealing that these proteins also share primary functions in maintaining vessel integrity. ${ }^{37}$ The decrease in MAGP-1 could account for an increased TGF- $\beta$ signaling ${ }^{37}$ and a decreased Notch1 signaling activation. ${ }^{38}$ Our results would imply that the relative lack of MAGP-1 would help compromise the elastic structure of autografts.

\section{Testican-2}

Ross autografts expressed significantly greater amounts of Testican-2 than PA control samples. Similar findings occurred in the dilated aortic media of patients with non-syndromic thoracic AA aneurysms. ${ }^{24}$ Testican-2 was first described as an unnamed chondroitin/heparan sulfate proteoglycan in seminal plasma. Later, it was found during the screening of a human cDNA library using a sequence-tag related to BM-40/osteonectin/SPARC and was shown to be expressed mainly in the brain. ${ }^{39}$ Since BM-40 is an ECM molecule acting as a modulator of cell adhesion and proliferation, Testican-2 may partake in tissue remodeling. By interacting with other testican family protein members, it helps activate membrane-type matrix metalloproteinases, ${ }^{40}$ favoring PA wall dilation. However, the physiological role of Testican-2 as a component of vascular wall ECM remains to be clarified.

\section{Cystathionine $\gamma$-Lyase}

Ross autografts expressed similar amounts of only the 42-kDa CTH isoform as PA and AA control samples did. Conversely, non-syndromic thoracic AA aneurysms and AA control samples more intensely expressed 2 isoforms, ie, 38- and 42-KDa, of CTH. ${ }^{23}$ The endogenous $\mathrm{CTH} / \mathrm{H}_{2} \mathrm{~S}$ system acts as a modulator of cellular proliferation and/or apoptosis of VSMCs. ${ }^{41}$ Abnormal metabolism and 
functions of the $\mathrm{CTH} / \mathrm{H}_{2} \mathrm{~S}$ pathway have been linked to different cardiovascular diseases. However, in Ross autografts, CTH expression is unchanged versus PA control samples. Hence, the unmodified $\mathrm{CTH} / \mathrm{H}_{2} \mathrm{~S}$ pathway is not likely to play any role in autograft dilation.

\section{Cell Signaling}

Jagged1/Notch1. The evolutionarily conserved Notch1 signaling pathway is highly involved in VSMC differentiation and fate determination during embryo-fetal development, whereas in adult age it regulates tissue physiological processes and stem cell maintenance through Notch1 binding a specific extracellular ligand, eg, JAG1 $^{42,43}$ Mutations in JAG and NOTCH genes frequently occur in human vascular diseases. In the present Ross autografts, we identified a significant upregulation of the soluble JAG1 42-kDa protein fragment, whereas NICD was markedly reduced. Conversely, both protein fragments are practically undetectable in AA control samples. In the canonical Notch signaling pathway, NICD released by Nocth1 after ligand-receptor engagement shuttles to the nucleus acting as a transcription cofactor. $^{42}$ The extracellular soluble $42-\mathrm{kDa}$ JAG1 fragment is produced by an active thrombin released from activated platelets within large thoracic AA aneurysms of any etiology. ${ }^{23,44}$ Although its functions are as yet not fully understood, the soluble JAG1 fragment inhibits JAG1 holoprotein $\cdot$ Notch1 signaling by acting as a dominantnegative ligand, ${ }^{44}$ and hence cuts down cell migration and adhesion likely by altering the formation of focal adhesion complexes. ${ }^{45}$ Moreover, the soluble JAG1 fragment inhibits the proliferation of VSMCs by blocking downstream Notch signaling. ${ }^{46}$ Therefore, our findings indicate that in Ross pulmonary autografts a hindered JAG1 Notch1 signaling would obstruct tissue remodeling through the hyperproduction of the soluble JAG1 fragment and the hypoproduction of NICD. By negatively impacting on cell-to-cell and cell-to-ECM interactions, VSMCs migration, and contractile differentiation these opposite changes would favor autografts wall dilation.

EDA/EDA2R. EDA is a ligand belonging to the TNF family that binds 2 TNF receptors, ie, EDAR and its orthologue EDA2R. ${ }^{47}$ EDAR signaling is required for ectodermal organ development across vertebrate species. ${ }^{48}$ Notably, PA trunk VSMCs together with AA trunk and arch SMCs are neuroectoderm-derived. ${ }^{49,50}$ The epithelial overexpression of EDAR goes together with an up-regulated BMP4 in the skin mesenchyme, suggesting that BMP4 is an indirect target of EDAR signaling. ${ }^{48}$ BMP4 also plays an important role in promoting pulmonary vascular remodeling. ${ }^{51}$ Interestingly, in the present Ross autografts the considerably increased levels of EDA2R protein are not coupled with any change in EDA ligand expression. Hence, an altered or imbalanced expression of the EDA.EDA2R complex impacting on EDA2R signaling would occur in Rossmaladapted cases. This might negatively affect autograft wall remodeling. The effects of BMP2 and BMP4 on VSMCs have been evaluated in few studies concerning pulmonary vasculature; as yet, their relationships with VSMCs of other sites are not understood. ${ }^{52,53}$ Hence, any crosstalk between EDA2R and BMP4 signaling pathways remains to be explored in both Ross autografts and PA control samples.

\section{Clinical Implications}

Although the Ross procedure allows unsurpassed survival and life quality in children and young adults requiring aortic valve replacement, ${ }^{1-3}$ autograft failure needing reoperation increasingly occurs in the subsequent second and third decade. ${ }^{1,2,11,54}$ Autograft root dilation, be it progressive or not, $^{13}$ causes an increased mechanical shear stress leading to valve dysfunction and, eventually, failure. ${ }^{4-7}$ This questions the pulmonary valve and root autograft ability to remodel into an aortic phenotype and to withstand systemic circulation for a life-time. ${ }^{13-16}$ Scant basic research data document remodeling of autografts once chronically exposed to systemic circulation. Rabkin-Aikawa and colleagues ${ }^{21}$ suggested the autograft leaflets remodel into an aortic-like phenotype. The outstanding long-term results of Ross operation, when performed as a subcoronary implant (ie, with the excision of the pulmonary autograft vascular tissue ${ }^{2}$ ), indirectly support their view. However, evidence by Schoof and colleagues questions this idea. ${ }^{19}$ Conversely, greater consensus exists about the PA vascular wall inability to ultimately remodel into an aortic phenotype, ${ }^{19,21}$ although in one animal model using a semiresorbable composite scaffold reinforcing the artery wall a positive remodeling of the PA was observed. ${ }^{55}$ In human pathology, however, the intimal thickening, medial elastin fragmentation, and adventitial fibrosis consistently observed in the explanted autografts wall justify the elasticity loss associated with dilation. ${ }^{19,21}$ In addition SMCs, the main local producers of collagen and elastin, appear hypertrophic and realigned, indicating an active rearrangement. ${ }^{19}$

The present proteomic study offers novel mechanistic insights into previously described histopathologic changes. ${ }^{19}$ Contrary to previous studies in which tissue samples were from vascular tissue placed above the sinotubular junction, the current investigation focused on pulmonary autograft (and control PA) tissue exclusively collected from sinus of Valsalva. This has relevant implications, given the distinct embryological origins of arterial roots and of great arteries possibly affecting their ability to remodel into neo-aortic phenotype. ${ }^{22}$ Moreover, the proteomic changes reported herein were dramatic even in moderately dilated neo-aortic roots $(<5.0 \mathrm{~cm})$ currently not considered an indication for elective reoperation. Whether this suggests 
to reassess reintervention timing in Ross patients remains undecided.

\section{Limitations of the Study}

The present study is limited by the relatively small patient population, even though this limitation affects most research investigating mechanisms of disease processes involving pulmonary autografts. In addition, like any study on autograft explants, the present work cannot document molecular changes, if any, occurring in the neo-aortic root of patients with no autograft dilation. Nonetheless, the proteomic findings related to ECM components, intercellular signaling, and cell adhesion, which are distinct from normal PA and AA, but also from aneurysmal AA, still allow to draw some inferences. ${ }^{23,24}$

In conclusion, the pulmonary autograft root may undergo a maladaptive remodeling in an attempt to meet increased mechanical demands. This mechanism may have implications for all patients with "systemic" PA roots, including Ross patients, but also late survivors after the arterial switch, Damus-Kaye-Stansel, and Norwood operations.

\section{Conflict of Interest Statement}

Authors have nothing to disclose with regard to commercial support.

The authors are grateful to Maddalena Marconi, $\mathrm{PhD}$, for her skillful technical assistance.

\section{References}

1. Sievers HH, Stierle U, Petersen M, Klotz S, Richardt D, Diwoky M, et al. Valve performance classification in 630 subcoronary Ross patients over 22 years. $J$ Thorac Cardiovasc Surg. 2018;156:79-86.

2. David TE, Ouzounian M, David CM, Lafreniere-Roula M, Manlhiot C. Late results of the Ross procedure. J Thorac Cardiovasc Surg. 2019;157:201-8.

3. Luciani GB, Favaro A, Casali G, Santini F, Mazzucco A. The Ross operation in the young: a 10-year experience. Ann Thorac Surg. 2005;80:2271-7.

4. David TE, Omran A, Ivanov J, Armstrong S, de Sa MP, Sonnenberg B, et al. Dilation of the pulmonary autograft after the Ross procedure. J Thorac Cardiovasc Surg. 2000;119:210-20.

5. Luciani GB, Casali G, Favaro A, Prioli MA, Barozzi L, Santini F, et al. Fate of the aortic root late after Ross operation. Circulation. 2003;108(suppl 1):II61-7.

6. Klieverik LM, Takkenberg JJ, Bekkers JA, Roos-Hesselink JW, Witsenburg M, Bogers AJ. The Ross operation: a Trojan horse? Eur Heart J. 2007;28: 1993-2000

7. Stulak JM, Burkhart HM, Sundt TM III, Connolly HM, Suri RM, Schaff HV, et al. Spectrum and outcome of reoperations after the Ross procedure. Circulation. 2010;122:1153-8.

8. El-Hamamsy I, Eryigit Z, Stevens LM, Sarang Z, George R, Clark L, et al. Longterm outcomes after autograft versus homograft aortic root replacement in adults with aortic valve disease: a randomised controlled trial. Lancet. 2010;376; 524-31.

9. Sievers HH, Hanke T, Stierle U, Bechtel MF, Graf B, Robinson DR, et al. A critical reappraisal of the Ross operation: renaissance of the subcoronary implantation technique? Circulation. 2006:114:I504-11.

10. Mazine A, Rocha RV, El-Hamamsy I, Ouzounian M, Yanagawa B, Bhatt DL, et al. Ross procedure vs mechanical aortic valve replacement in adults: a systematic review and meta-analysis. JAMA Cardiol. 2018;3:978-87.

11. Sievers HH. Excellent results up to 20 years with the Ross operation, albeit with some sobering. J Thorac Cardiovasc Surg. 2019;157:209-10.
12. Carr-White GS, Afoke A, Birks EJ, Hughes S, O'Halloran A, Glennen S, et al Aortic root characteristics of human pulmonary autografts. Circulation. 2000; 102:III15-21.

13. Schmidtke C, Bechtel JFM, Hueppe M, Noetzold A, Sievers HH. Size and distensibility of the aortic root and aortic valve function after different techniques of the Ross procedure. J Thorac Cardiovasc Surg. 2000;119:990-7.

14. Grotenhuis HB, Westenberg JJ, Doornbos J, Kroft LJ, Schoof PH Hazekamp MG, et al. Aortic root dysfunctioning and its effect on left ventricular function in Ross procedure patients assessed with magnetic resonance imaging. Am Heart J. 2006;152:975.e1-8.

15. Puranik R, Tsang VT, Broadley A, Nordmeyer J, Lurz P, Muthialu N, et al. Functional outcomes after the Ross (pulmonary autograft) procedure assessed with magnetic resonance imaging and cardiopulmonary exercise testing. Heart. 2010;96:304-8.

16. Luciani GB, Viscardi F, Puppini G, Faggian G, Mazzucco A. Aortic root physiology late after a "perfect" ross operation: magnetic resonance imaging study of three operative techniques. Artif Organs. 2011;35:1142-50.

17. Mookhoek A, Krishnan K, Chitsaz S, Kuang H, Ge L, Schoof PH, et al. Biomechanics of failed pulmonary autografts compared to native aortic roots. Ann Thorac Surg. 2017;103:1482-8.

18. Schoof PH, Gittenberger-De Groot AC, De Heer E, Bruijn JA, Hazekamp MG, Huysmans HA. Remodeling of the porcine pulmonary autograft wall in the aortic position. J Thorac Cardiovasc Surg. 2000;120:55-65.

19. Schoof PH, Takkenberg JJ, van Suylen RJ, Zondervan PE, Hazekamp MG Dion RA, et al. Degeneration of the pulmonary autograft: an explant study. $J$ Thorac Cardiovasc Surg. 2006;132:1426-32.

20. Mookhoek A, de Heer E, Bogers AJ, Takkenberg JJ, Schoof PH. Pulmonary autograft valve explants show typical degeneration. J Thorac Cardiovasc Surg. 2010; 139:1416-9

21. Rabkin-Aikawa E, Aikawa M, Farber M, Kratz JR, Garcia-Cardena GG, Kouchoukos NT, et al. Clinical pulmonary autograft valves: pathologic evidence of adaptive remodeling in the aortic site. J Thorac Cardiovasc Surg. 2004;128: 552-61.

22. Lalezari S, Hazekamp MG, Bartelings MM, Schoof PH, Gittenberger-De Groot AC. Pulmonary artery remodeling in transposition of the great arteries: relevance for neoaortic root dilatation. J Thorac Cardiovasc Surg. 2003;126:1053-60.

23. Chiarini A, Onorati F, Marconi M, Pasquali A, Patuzzo C, Malashicheva A, et al. Studies on sporadic non-syndromic thoracic aortic aneurysms: I. Deregulation of Jagged/Notch 1 homeostasis and selection of synthetic/secretor phenotype smooth muscle cells. Eur J Prev Cardiol. 2018;25(1_suppl):42-50.

24. Chiarini A, Onorati F, Marconi M, Pasquali A, Patuzzo C, Malashicheva A, et al Studies on sporadic non-syndromic thoracic aortic aneurysms: II. Alterations of extra-cellular matrix components and focal adhesion proteins. Eur J Prev Cardiol. 2018;25(1_suppl):51-8.

25. Luciani GB, Viscardi F, Pilati M, Prioli AM, Faggian G, Mazzucco A. The RossYacoub procedure for aneurysmal autograft roots: a strategy to preserve autologous pulmonary valves. J Thorac Cardiovasc Surg. 2010;139:536-42.

26. Gabbiani G, Schmid E, Winter S, Chaponnier C, de Ckhastonay C, Vandekerckhove J, et al. Vascular smooth muscle cells differ from other smooth muscle cells: predominance of vimentin filaments and a specific alpha-type actin. Proc Natl Acad Sci U S A. 1981;78:298-302.

27. Tang DD, Wu MF, Opazo Saez AM, Gunst SJ. The focal adhesion protein paxillin regulates contraction in canine tracheal smooth muscle. J Physiol. 2002;542 501-13.

28. Kielty CM, Sherratt MJ, Shuttleworth CA. Elastic fibres. J Cell Sci. 2002;115(P 14):2817-28.

29. Nagpure BV, Bian J-S. Interaction of hydrogen sulfide with nitric oxide in the cardiovascular system. Oxid Med Cell Longev. 2016;2016:6904327.

30. D'Souza B, Miyamoto A, Weinmaster G. The many facets of Notch ligands Oncogene. 2008;27:5148-67.

31. Schweisguth F. Regulation of notch signaling activity. Curr Biol. 2004;14: R129-38.

32. Tang DD, Gerlach BD. The roles and regulation of the actin cytoskeleton, intermediate filaments and microtubules in smooth muscle cell migration. Respir Res. 2017; 18:54.

33. Schiffers PM, Henrion D, Boulanger CM, Colucci-Guyon E, Langa-Vuves F, van Essen $\mathrm{H}$, et al. Altered flow-induced arterial remodeling in vimentin-deficient mice. Arterioscler Throm Vasc Biol. 2000;20:611-6.

34. Lacolley P, Regnault V, Segers P, Laurent S. Vascular smooth muscle cells and arterial stiffening: relevance in development, aging, and disease. Physiol Rev. 2017;97:1555-617. 
35. Veith C, Marsh LM, Wygrecka M, Rutschmann K, Seeger W, Weissmann N, et al. Paxillin regulates pulmonary arterial smooth muscle cell function in pulmonary hypertension. Am J Pathol. 2012;181:1621-33.

36. Barbier M, Gross MS, Aubart M, Hanna N, Kessler K, Guo DC, et al. MFAP5 loss-of-function mutations underscore the involvement of matrix alteration in the pathogenesis of familial thoracic aortic aneurysms and dissections. Am J Hum Genet. 2014;95:736-43.

37. Craft CS, Broekelmann TJ, Mecham RP. Microfibril-associated glycoproteins MAGP-1 and MAGP-2 in disease. Matrix Biol. 2018;71-2. 100-111.

38. Miyamoto A, Lau R, Hein PW, Shipley JM, Weinmaster G. Microfibrillar proteins MAGP-1 and MAGP-2 induce Notch1 extracellular domain dissociation and receptor activation. J Biol Chem. 2006;281:10089-97.

39. Vannahme C, Schubel S, Herud M, Gosling S, Hulsmann H, Paulsson M, et al. Molecular cloning of testican 2: defining a novel calcium-binding proteoglycan family expressed in brain. J Neurochem. 1999;73:12-20.

40. Nakada M, Miyamori H, Yamashita J, Sato H. Testican 2 abrogates inhibition of membrane-type matrix metalloproteinases by other testican family proteins. Cancer Res. 2003;63:3364-9.

41. Yang G, Wu LN, Bryan S, Khaper N, Mani S, Wang R. Cystathionine gammalyase deficiency and overproliferation of smooth muscle cells. Cardiovasc Res. 2010;86:487-95.

42. Baeten JT, Lilly B. Notch signaling in vascular smooth muscle cells. Adv Pharmacol. 2017;78:351-82.

43. Lin C-H, Lilly B. Notch signaling governs phenotypic modulation of smooth muscle cells. Vascul Pharmacol. 2014;60:88-96.

44. Duarte M, Kolev V, Kacer D, Mouta-Bellum C, Soldi R, Graziani I, et al. Novel cross-talk between three cardiovascular regulators: thrombin cleavage fragment of Jagged1 induced fibroblast growth factor 1 expression and release. $\mathrm{Mol}$ Biol Cell. 2008;19:4863-74

45. Lindner V, Booth C, Prudovsky I, Small D, Maciag T, Liaw L. Members of the Jagged/Notch gene families are expressed in injured arteries and regulate cell phenotype via alterations in cell matrix and cell-cell interaction. Am J Pathol. 2001;159:875-83.

46. Zhou X, Xiao Y, Mao Z, Huang J, Geng Q, Wang W, et al. Soluble Jagged-1 inhibits restenosis of vein graft by attenuating Notch signaling. Microvasc Res. 2015;100:9-16.
47. Yan M, Zhang Z, Brady JR, Schilbach S, Fairbrother WJ, Dixit VM. Identification of a novel death domain-containing adaptor molecule for ectodysplasin-A receptor that is mutated in crinkled mice. Curr Biol. 2002; 12:409-13.

48. Pispa J, Thesleff I. Mechanisms of ectodermal organogenesis. Dev Biol. 2003; 262:195-205.

49. Jiang X, Rowitch DH, Soriano P, McMahon AP, Sucov HM. Fate of the mammalian cardiac neural crest. Development. 2000;127:1607-16.

50. Sinha S, Iyer D, Granata A. Embryonic origins of human vascular smooth muscle cells: implications for in vitro modeling and clinical application. Cell Mol Life Sci. 2014;71:2271-88.

51. Arciniegas E, Frid MG, Douglas IS, Stenmark KR. Perspectives on endothelialto-mesenchymal transition: potential contribution to vascular remodeling in chronic pulmonary hypertension. Am J Physiol Lung Cell Mol Physiol. 2007; 293:L1-8.

52. Anderson L, Lowery JW, Frank DB, Novitskaya T, Jones M, Mortlock DP, et al. Bmp2 and Bmp4 exert opposing effects in hypoxic pulmonary hypertension. Am J Physiol Regul Integr Comp Physiol. 2010;298:R833-42.

53. Frank DB, Abtahi A, Yamaguchi DJ, Manning S, Shyr Y, Pozzi A, et al. Bone morphogenetic protein 4 promotes pulmonary vascular remodeling in hypoxic pulmonary hypertension. Circ Res. 2005;97:496-504.

54. Sharifulin R, Bogachev-Prokophiev A, Zheleznev S, Demin I, Pivkin A, Afanasyev A, et al. Factors impacting long-term pulmonary autograft durability after the Ross procedure. J Thorac Cardiovasc Surg. 2019;157: 134-41.e3.

55. Nappi F, Fraldi M, Spadaccio C, Carotenuto AR, Montagnani S, Castaldo C, et al. Biomechanisms drive histological wall remodeling of neoaortic root: a mathematical model to study the expression levels of ki 67 , metalloprotease, and apoptosis transition. J Biomed Mater Res A. 2016; 104A:2785-93.

Key Words: pulmonary artery, root autografts, maladaptive remodeling, Ross procedure, proteomics, ascending aorta, aneurysm 


\section{APPENDIX E1. METHODS \\ Pulmonary and Aortic Media Protein Lysate Prefractionation}

Control and pulmonary autograft media tissue samples were cut into small pieces, ground in a mortar, and dissolved with isoelectrofocusing (IEF) denaturant buffer $(4 \mathrm{~mL}$ for each $\mathrm{g}$ of minced tissue [wet weight]: $7.7 \mathrm{M}$ urea, $2.2 \mathrm{M}$ thiourea, 4,4\% CHAPS (3-[(3-cholamido-propyl) dimethyl-ammonium]-1-propanesulfonate), $20 \mathrm{mM}$ dithiothreitol, and protease inhibitors cocktail [Roche, Basel, Switzerland]) and homogenized on ice by means of Ultra-Turrax (IKA, Staufen, Germany). Ten microliters of $1 \mathrm{M}$ Tris base were added to each milliliter of lysate and the resulting lysate was alkylated with N,N-dimethylacrylamide. After a 30-minute incubation at room temperature, dithiothreitol was added to quench any excess of N,N-dimethylacrylamide. The resulting homogenate was centrifuged at $16,000 \times g$ for 20 minutes at $4{ }^{\circ} \mathrm{C}$. Protein concentration was determined by Bradford's method. Then, the proteins were prefractionated using the narrow $\mathrm{pH}$ range ZOOM-IEF Fractionator (Invitrogen/ Thermo Fisher Scientific, Waltham, Mass) according to the supplier's protocol. Thus, sample protein concentrations were adjusted to $0.6 \mathrm{mg} / \mathrm{mL}$ and $670 \mu \mathrm{L}$ were loaded onto 5 different $\mathrm{pH}$ chambers (ie, $\mathrm{pH} 3.0-4.6, \mathrm{pH} 4.6-5.4, \mathrm{pH}$ 5.4-6.2, $\mathrm{pH} 6.2-7.0$, and $\mathrm{pH} 7.0-10.0$, respectively) in the ZOOM-IEF Fractionator (Invitrogen/Thermo Fisher Scientific). Fractionations were processed at $100 \mathrm{~V}$ for 20 minutes, $200 \mathrm{~V}$ for 80 minutes, followed by $600 \mathrm{~V}$ for 80 minutes. The fractions obtained were collected and stored at $-80^{\circ} \mathrm{C}$ until used for 2-dimensional gel electrophoresis (2-DE).

\section{Two-Dimensional Gel Electrophoresis}

Sample protein fractions were first separated according to their isoeletric point range on 7-cm IPG ZOOM strips $(\mathrm{pH}$ $3-10, \mathrm{pH} 4.5-5.5, \mathrm{pH} 5.3-6.3, \mathrm{pH} 6.1-7.1$, and $\mathrm{pH}$ 6-10) and then were separated according to their $\mathrm{M}_{\mathrm{r}}$ in a NuPAGE Novex 4\%-12\% Bis-Tris ZOOM gel (Thermo Fisher Scientific). Protein spots separated on 2-DE gels were visualized using a mass spectrometry (MS)-compatible staining, ie, SimplyBlue Safe Stain (Invitrogen/Thermo Fisher Scientific), scanned, and analyzed using Delta2D software (version 4.0, Greifswald, Germany). Based on the ongoing findings, further proteomic analysis was also focused on $\mathrm{pH}$ 4.5-5.5, $\mathrm{pH}$ 5.3-6.3 2-DE gels.

\section{In-Gel Protein Digestion and Matrix-Assisted-Laser- Desorption-Ionization-Time of Flight (MALDI- TOF)/MS, Peptide Mass Fingerprinting (PMF), and Bioinformatic Analyses}

The tryptic in-gel digestion and desalting steps were performed using 96-well ZipPlate micro-SPE plates (Millipore, Burlington, Mass) according to the manufacturer's instructions as previously described. ${ }^{\mathrm{E} 1} \mathrm{Ex}-$ tracted peptides were directly applied onto a target that was loaded with a thin layer of CHCA ( $\alpha$-cyano-4hydroxy-cinnamic acid) matrix (Laserbiolabs, Valbonne, France) and analyzed by means of the Voyager De PRO MALDI-TOF/MS (Applied Biosystems, Foster City, Calif) operating in the reflector mode. An accelerating voltage of $25 \mathrm{kV}$ was used for PMF. Data processing and protein identification were accomplished using Data Explorer software (Applied Biosystems) and the Protein Prospector's MS-Fit program (Version 5.22.1; University of California). These mass lists were searched against the Swiss-Prot databases. Proteins were evaluated by considering their MOlecular Weight SEarch score, ie, the number of matched peptides, and the percent coverage of the protein sequence. Search parameters allowed for one missed cleavage site. Peptide mass tolerance was set to $100 \mathrm{ppm}$ and methionine oxidation, acrylamide modified cysteine, cysteine alkylation (carbamidomethylation), and phosphorylation of serines, threonines, and tyrosines were taken into consideration as possible modifications. Searches were taxonomically restricted to Homo sapiens as previously detailed by Chiarini et al. ${ }^{\text {E1 }}$

\section{Western Immunoblotting}

Pulmonary media protein lysates were separated by electrophoresis and subjected to Western immunoblotting analysis as previously described. ${ }^{\mathrm{E}}$ Equal amounts (10-20 $\mu \mathrm{g}$ ) of protein from individual control or pulmonary autograft media protein lysates were loaded on a NuPAGE Novex $10 \%$, or $3 \%-8 \%$, or $4 \%-12 \%$ Bis-Tris polyacrylamide gel (Invitrogen/Thermo Fisher Scientific). After electrophoresis in NuPAGE MOPS SDS Running Buffer or in NuPAGE Tris-Acetate SDS Running Buffer using the Xcell SureLock Mini-Cell (Invitrogen/Thermo Fisher Scientific; 50-minute run-time at $200 \mathrm{~V}$ constant), proteins were blotted onto nitrocellulose membranes (0.45 $\mu \mathrm{m}$; Pall Life Sciences, Port Washington, NY). The membranes were probed with the specific rabbit polyclonal antibodies against human: paxillin $(1 \mu \mathrm{g} / \mathrm{mL}$; Santa Cruz Biotechnology, Heidelberg, Germany); Jagged1 (ab7771, $1 \mu \mathrm{g} / \mathrm{mL}$; Abcam, Cambridge, United Kingdom); or mouse monoclonal antibodies against microfibril-associated glycoprotein1 (1:1000; Abnova, Taipei, Taiwan); ectodysplasin ( $1 \mu \mathrm{g} / \mathrm{mL}$; Abnova); Ectodysplasin Receptor (1 $\mu \mathrm{g} / \mathrm{mL}$, Abnova); cystathionine $\gamma$-lyase $(1 \mu \mathrm{g} / \mathrm{mL}$; Abnova); $\alpha$-smooth muscle actin (1:1000; Epitomics, Inc, Burlingame, Calif) or goat polyclonal antibody against human SPOCK2 (Testican-2); Notch1(S-20); Vimentin (all 3 at $1 \mu \mathrm{g} / \mathrm{mL}$, from Santa Cruz Biotechnology). After the incubation with alkaline phosphatase-conjugated proper secondary antibodies (Santa Cruz Biotechnology), blots were stained with BCIP/NBT liquid substrate reagent (Sigma). Developed blots were photographed with an 
Olympus 3300 digital camera, and the determination of the $\mathrm{M}_{\mathrm{r}}$ and the densitometric analysis of each specific protein band were carried out using Sigmagel software (Jandel Corp, Erkrath, Germany).

\section{Statistical Analysis}

Descriptive statistical analyses were carried out by one of us (U.A.) using the Analyse-it software package (www.analyse-it.com). Normality was assessed via the Shapiro-Wilk test and the equality of variance in different sample groups via the Bartlett's test.

Welch analysis of variance with Dunnet's test for multiple comparisons of the densitometric integrated intensity results concerning each protein's specific immunoblot bands from PA control versus pulmonary autograft or AA control groups was applied, and $P<.05$ was considered as statistically significant. When the Shapiro-Wilk test revealed that a normal distribution could not be assumed, the one-way nonparametric analysis of variance Kruskal-Wallis test with Steel-Dwass-
Critchlow-Fligner test for the statistical comparisons of the densitometric integrated intensity results concerning each protein's specific immunoblot bands from PA control versus pulmonary autograft or AA control groups was applied and a $P<.05$ was considered as statistically significant. The Student $t$ test was used when only 2 independent groups (PA control and pulmonary autograft) were compared. The data are shown as dot plots of each protein specific band densitometry values and were graphically represented as skeletal notched box charts including from the first to the third quartiles, with the median indicated by a transverse black line, and the minimum and maximum values as whiskers with end caps.

\section{E-Reference}

E1. Chiarini A, Marconi M, Pacchiana R, Dal Prà I, Wu J, Armato U. Role-shifting PKC $\zeta$ fosters its own proapoptotic destruction by complexing with $\mathrm{Bcl} 10$ at the nuclear envelope of human cervical carcinoma cells: a proteomic and biochemical study. J Proteome Res. 2012;11:3996-4012. 


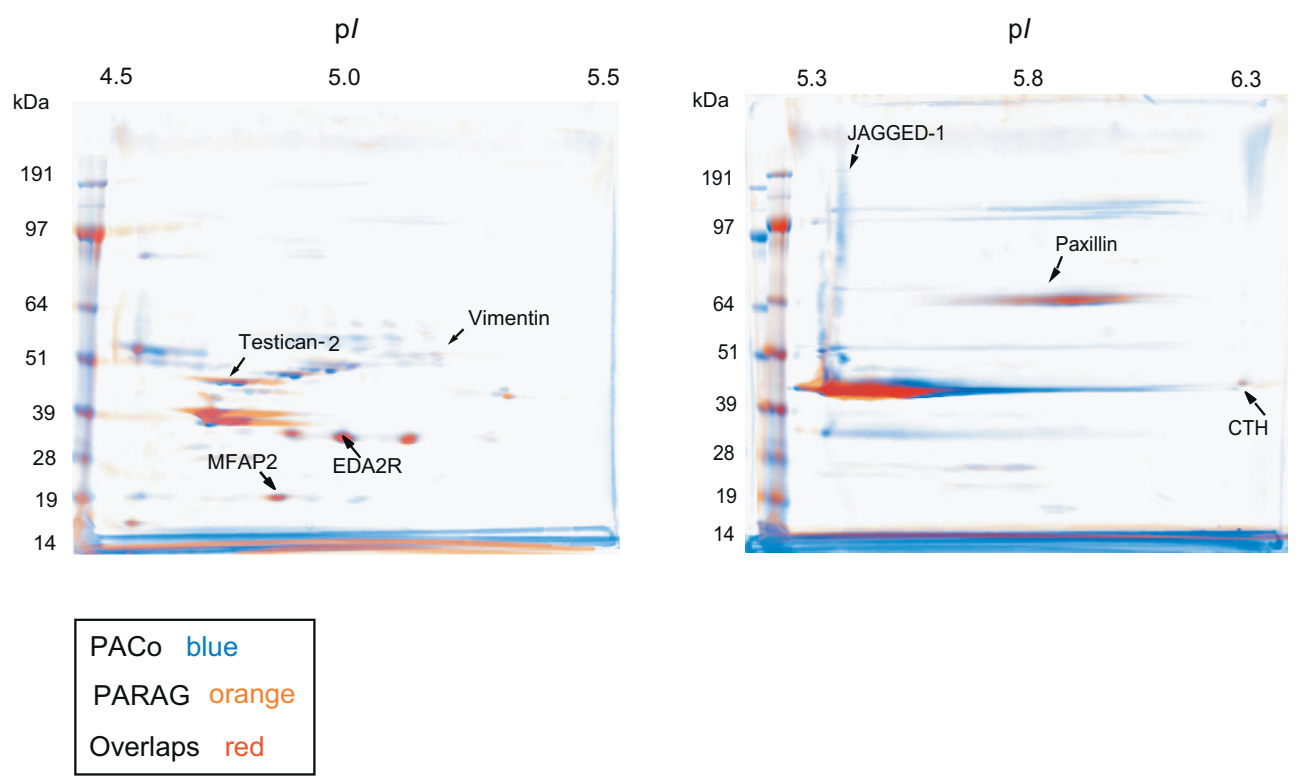

FIGURE E1. Two-dimensional gel electrophoresis gels of the 4.5-5.5 and 5.3-6.3 isoeletric point ranges illustrating the different proteomic profiles of media samples from pulmonary autograft (PARAG) (orange) versus PA control (PACo) (blue) lysates; overlaps are in red. pI, Isoeletric point; $M F A P 2$, microfibril-associated glycoprotein2; $E D A 2 R$, ectodysplasin receptor; $C T H$, cystathionine $\gamma$-lyase. 